\title{
Ralstonia solanacearum Encounters an Oxidative Environment During Tomato Infection
}

\author{
Zomary Flores-Cruz and Caitilyn Allen \\ Department of Plant Pathology, University of Wisconsin-Madison, Madison 53706, U.S.A.
}

Submitted 17 December 2008. Accepted 27 February 2009.

\begin{abstract}
Ralstonia solanacearum genes that are induced during tomato infection suggested that this pathogen encounters reactive oxygen species (ROS) during bacterial wilt pathogenesis. The genomes of $R$. solanacearum contain multiple redundant ROS-scavenging enzymes, indirect evidence that this pathogen experiences intense oxidative stress during its life cycle. Over $9 \%$ of the bacterium's plant-induced genes were also upregulated by hydrogen peroxide in culture, suggesting that oxidative stress may be linked to life in the plant host. Tomato leaves infected by $R$. solanacearum contained hydrogen peroxide, and concentrations of this ROS increased as pathogen populations increased. Mutagenesis of a plant-induced predicted peroxidase gene, $b c p$, resulted in an $R$. solanacearum strain with reduced ability to detoxify ROS in culture. The $b c p$ mutant caused slightly delayed bacterial wilt disease onset in tomato. Moreover, its virulence was significantly reduced on tobacco plants engineered to overproduce hydrogen peroxide, demonstrating that $\mathrm{Bcp}$ is necessary for detoxification of plantderived hydrogen peroxide and providing evidence that host ROS can limit the success of this pathogen. These results reveal that $R$. solanacearum is exposed to ROS during pathogenesis and that it has evolved a redundant and efficient oxidative stress response to adapt to the host environment and cause disease.
\end{abstract}

Ralstonia solanacearum is a soil-dwelling gram-negative bacterium that causes bacterial wilt disease in over 200 plant species (Hayward 1991). Due to its large host range and broad geographic distribution, this pathogen causes large crop losses worldwide, especially in developing tropical countries. The bacterium enters the host through wounded roots or sites of secondary root emergence; once inside a host, it quickly spreads and multiplies (Schell 2000). During plant infection, $R$. solanacearum effectively colonizes the xylem vessels, a nutrient-poor and microaerobic environment (Pegg 1985), where the bacterium nonetheless reaches populations of $10^{9}$ CFU/g of plant tissue (Schell 2000). R. solanacearum possesses diverse virulence factors that act quantitatively to cause disease; these include extracellular polysaccharide, cell-walldegrading enzymes, flagellar and twitching motility, chemotaxis, and type III secreted effectors (Arlat et al. 1992; Denny and Baek 1991; Gonzalez and Allen 2003; Kang et al. 2002; Kao et al. 1992; Liu et al. 2005; Tans-Kersten et al. 2001; Yao and Allen 2006). These virulence factors are controlled by a

Corresponding author: C. Allen; E-mail: cza@plantpath.wisc.edu

Present address of Z. Flores-Cruz: Department of Plant Pathology, University of Florida, Gainesville 32611, U.S.A. complex regulatory signal transduction pathway (Schell 2000) that responds to both environmental signals and the quorumsensing molecule 3-hydroxy palmitic acid methyl ester (Flavier et al. 1997). Although much is understood about these virulence factors and their regulation, little is known about how $R$. solanacearum adapts to effectively colonize, multiply, and spread in the host environment.

Promoter-trapping methods that operate in a specific environment (e.g., a host), commonly known as in vivo expression technology (IVET), have revealed the mechanisms bacteria use to adapt to their environments. IVET identifies genes needed during microbe-host interactions by selecting microbial promoters that are active during the interaction rather than relying on loss-of-function assays (Rediers et al. 2005). A previous IVET screen on $R$. solanacearum during midphase pathogenesis of tomato identified 153 in planta-expressed (ipx) genes (Brown and Allen 2004). Approximately $10 \%$ of these ipx genes are predicted to encode proteins involved in stress response, notably the oxidative stress response, providing indirect evidence that $R$. solanacearum is exposed to an oxidative environment during plant pathogenesis.

When plants recognize potential pathogens, they produce an oxidative burst that consists of superoxide, hydrogen peroxide, and hydroxyl radicals. This oxidative burst, which triggers plant defense signal transduction pathways, occurs in two phases: phase I is short-lived, nonspecific, and occurs within minutes after pathogen recognition and phase II is prolonged and occurs 1.5 to $3 \mathrm{~h}$ after pathogen detection (Lamb and Dixon 1997). Phase II of the oxidative burst often leads to disease resistance via the hypersensitive response and the induction of host defense genes (Apel and Hirt 2004). Reactive oxygen species (ROS) generation is mainly attributed to cell-wall-bound peroxidases and NADPH oxidases, similar to those found in macrophages (Torres and Dangl 2005). It is believed that the oxidative burst may have direct antimicrobial effects; however, the amounts of ROS experienced by pathogens during host infection are unknown.

Because ROS cause severe macromolecule damage leading to mutations and cell death, bacteria have evolved complex, specific, and tightly regulated oxidative stress responses to protect themselves (Imlay 2008). The bacterial oxidative stress response includes proteins involved in signal transduction and regulation, ROS-scavenging enzymes, and repair of oxidative damage (Loprasert et al. 1996). Plant-associated bacteria express several oxidative stress response genes during interactions with their hosts (Okinaka et al. 2002; Rediers et al. 2005; Smith et al. 1996; Tamir-Ariel et al. 2007), and some are required for virulence. In Agrobacterium tumefaciens, katA (catalase) and $\operatorname{sodB}$ (superoxide dismutase) are necessary for tumorigenesis (Saenkham et al. 2007; Xu and Pan 2000) and Erwinia chrysanthemi sodA and msrA (methionine sulfoxide reductase) 
mutants have reduced virulence on African violets and chicory leaves, respectively (Hassouni et al. 1999; Santos et al. 2001). However, the effect of host-derived ROS and the role of the oxidative stress response have not been investigated in bacterial wilt disease or in any xylem-dwelling vascular wilt pathogen.

We hypothesized that $R$. solanacearum is exposed to plantderived ROS during plant pathogenesis and that the oxidative stress response genes of $R$. solanacearum are expressed in planta, where they contribute to survival and adaptation in the host and to disease development. In support of this hypothesis, we found that $R$. solanacearum is exposed to hydrogen peroxide in tomato tissue, and that this pathogen has several redundant oxidative stress response-encoding genes, some of which are expressed during pathogenesis. Our results suggest that the oxidative stress response of $R$. solanacearum is an important adaptation that contributes to its success inside its diverse plant hosts.

\section{RESULTS}

\section{R. solanacearum possesses multiple and redundant oxidative stress response genes.}

To identify elements of the oxidative stress response in $R$. solanacearum, we searched the complete genome of $R$. solanacearum GMI1000 (Salanoubat et al. 2002) for open reading frames (ORFs) encoding likely orthologs of well-characterized ROS-scavenging enzymes from other bacteria. Amino acid sequences of the predicted scavenging enzymes from GMI1000 were used to search the $R$. solanacearum UW551 8X draft genome (Gabriel et al. 2006) via BLASTP (Altschul et al. 1997). This process identified genes predicted to encode multiple and redundant ROS-scavenging enzymes in both genomes (Table 1). The predicted ROS-scavenging enzymes in the two $R$. solanacearum genomes share high amino acid identities (83 to $99 \%$ ) and were present in both strains, with the exception of one of the two katG genes, which was absent from the UW551 strain genome (Table 1). Predicted proteins include at least five peroxidases, two alkyl hydroperoxide reductase systems, two catalases, and two superoxide dismutases. One of the predicted peroxidases, bacterioferritin co-migratory protein (Bcp), was previously identified as an ipx gene in an IVET screen of $R$. solanacearum for promoters specifically upregulated during tomato pathogenesis (Brown and Allen 2004). Bacteria commonly regulate the oxidative stress response with OxyR, for the hydrogen peroxide stress response, and SoxRS, for the superoxide stress response (Imlay 2008). An
OxyR ortholog (closest match outside the genus Ralstonia: Bordetella avium; $\mathrm{E}=2 \mathrm{e}-128$ ) was found in the available genomes of $R$. solanacearum. However, no likely SoxRS ortho$\log$ s were found using a cutoff of $35 \%$ amino acid identity over the length of the proteins.

\section{Several $\boldsymbol{R}$. solanacearum ipx genes are also upregulated by hydrogen peroxide.}

To test whether other ipx genes, which included many genes of unknown function, are part of the $R$. solanacearum oxidative stress response, we determined whether hydrogen peroxide could induce expression of the 153 ipx fusion strains. The ipx strains carry transcriptional fusions to the promoterless uidA (gus) reporter gene. Expression of the gus reporter gene in the presence of 5-bromo-4-chloro-3-indolyl glucuronide (XGluc) generates a visible blue pigment (Jefferson et al. 1986). On unmodified rich medium, the ipx colonies were white, indicating lack of fusion gene expression (Brown and Allen 2004). However, 14 ipx fusions (9\% of all ipx genes tested) were blue on rich medium containing hydrogen peroxide (Table 2). Predicted functions of ipx genes induced by hydrogen peroxide include hydrogen peroxide detoxification; amino acid, nucleotide, and ascorbate metabolism; sugar transport; signal peptides; transcriptional regulators; and several genes of unknown function.

One of the hydrogen peroxide-inducible ipx fusions, ipx 142 , was originally described as backwards; that is, inserted near a promoter in the opposite orientation with respect to the uidA gene (Brown and Allen 2004). However, reanalysis of the genomic context around the predicted promoter of ipx 142 in the GMI1000 genome indicates that trxA (Rsc1188, encoding a putative thioredoxin, a protein involved in the bacterial oxidative stress response) is in the correct orientation with respect to the uidA gene, suggesting that the $\operatorname{tr} x A$ promoter drives uidA expression in this strain (Fig. 1A).

\section{$R$. solanacearum is exposed to hydrogen peroxide in tomato plants.}

To determine whether $R$. solanacearum experiences ROS during growth in an important host, we used a stain specific for hydrogen peroxide during $R$. solanacearum infection of tomato leaves. Oxidation of 3,3-diaminobenzidine (DAB) by hydrogen peroxide creates a visible brown precipitate that can be qualitatively assessed (Orozco-Cardenas and Ryan 1999). Leaves infiltrated with concentrations of $R$. solanacearum cells ranging from $5 \times 10^{5}$ to $1 \times 10^{9} \mathrm{CFU} / \mathrm{ml}$ were cut at the petiole

Table 1. Predicted reactive oxygen species-scavenging enzymes in Ralstonia solanacearum genome sequences

\begin{tabular}{|c|c|c|c|}
\hline \multirow[b]{2}{*}{ Predicted function (gene name) } & \multicolumn{2}{|c|}{ Gene number ${ }^{a}$} & \multirow[b]{2}{*}{$E$ value, relevant match } \\
\hline & GMI1000 & UW551 & \\
\hline AhpC/TSA family peroxidase & $\mathrm{RSc} 0754$ & RRSL01499 & 1e-108, Pseudomonas putida \\
\hline Glutathione peroxidase & $\mathrm{RSc} 2674$ & RRSL03227 & 3e-85, Ralstonia pickettii \\
\hline Glutathione peroxidase & $\mathrm{RSc} 0307$ & RRSL01638 & 3e-46, Xanthomonas campestris pv. vesicatoria \\
\hline Thiol peroxidase $(t p x)$ & RSc 2790 & RRSL02667 & 5e-59, P. fluorescens Pf-5 \\
\hline Peroxidase $(b c p)$ & RSc1317 & RRSL00135 & 2e-61, P.fluorescens Pf0-1 \\
\hline Organic hydroperoxide resistance $(o h r)$ & RSp1107 & RRSL04748 & 3e-60, P. atrosepticum \\
\hline Alkyl hydroperoxide reductase $(a h p D)$ & RSc1645 & RRSL04570 & 4e-55, Bordetella petrii \\
\hline Alkyl hydroperoxide reductase (ahpC2) & RSc1646 & RRSL04571 & 4e-55, B. petrii \\
\hline Alkyl hydroperoxide reductase $(a h p C 1)$ & RSp0245 & RRSL01699 & 2e-95, X. axonopodis pv. citri \\
\hline Alkyl hydroperoxide reductase $(a h p F)$ & RSp0246 & RRSL01700 & 0.0, P. fluorescens $\mathrm{PfO}-1$ \\
\hline Catalase $(k a t G b)$ & RSc0775 & RRSL01521 & 0.0, Burkholderia pseudomallei \\
\hline Catalase (katGa) & $\mathrm{RSc} 0776$ & Absent & 9e-133, B. pseudomallei \\
\hline Catalase (katE) & RSp1581 & RRSL02532 & $0.0, P$. aeruginosa \\
\hline Superoxide dismutase $(\operatorname{sod} B)$ & $\mathrm{RSc} 2526$ & RRSL01451 & 1e-95, B. petrii \\
\hline Superoxide dismutase ( $\operatorname{sod} C)$ & $\mathrm{RSc} 2368$ & RRSL03640 & 2e-31, X. campestris pv. vesicatoria \\
\hline
\end{tabular}

a Name and numbers are according to GMI1000 and UW551 genomes (Gabriel et al. 2006; Salanoubat et al. 2002). Boldface denotes gene previously identified as plant-induced (Brown and Allen 2004). 
after $24 \mathrm{~h}$ of incubation and stained with DAB (Fig. 2) or sampled to determine bacterial population size (Table 3). Brown precipitate indicating hydrogen peroxide was visible in leaves inoculated with $5 \times 10^{6} \mathrm{CFU} / \mathrm{ml}$ and higher, and the stain intensity increased with cell concentration. Leaves inoculated with lower cell densities were indistinguishable from the mock-inoculated control (data not shown). Leaves containing large populations and showing tissue collapse and necrosis produced the most intense color (Fig. 2F).

Leaves of the bacterial wilt-tolerant tomato line Hawaii 7996 were also infused with $R$. solanacearum cells. Although this stain is qualitative and, thus, would not detect small differences in hydrogen peroxide concentrations, the intensity of the DAB stain in this line was similar to that in susceptible leaves inoculated with the same bacterial suspensions (data not shown). Leaves of both plants contained similar numbers of $R$. solanacearum cells at the time of DAB stain (Table 3).

\section{$R$. solanacearum bcp mutant K1317 has reduced ability} to detoxify $\mathrm{ROS}$ in culture.

To investigate the virulence contribution of the in planta-expressed and hydrogen peroxide-induced predicted peroxidase Bcp, we created a $b c p$ mutant strain, K1317 (Fig. 1B). The $R$. solanacearum-predicted Bcp was $39 \%$ identical at the amino acid level to the well-characterized E. coli Bcp over $95 \%$ of the protein sequence.

$R$. solanacearum K1317 grew as well as the wild type in minimal media supplemented with glucose and in susceptible tobacco leaves (cv. Bottom Special) (data not shown), suggesting that K1317 is not an auxotroph and does not have any general metabolic defects. However, K1317 was hypersensitive to hydrogen peroxide (Fig. 3A) and did not grow as well as its wild-type parent in media supplemented with the superoxidegenerating agent paraquat (Fig. 3B). Introduction of a wildtype copy of $b c p$ into K1317 partially restored a wild-type level of hydrogen peroxide resistance (Fig. 3A). Wild-type strain K60 and the K60-bcp mutant were significantly different from each other according to Fischer's least significant difference test $(P<0.05)$. However, the complemented mutant strain gave an intermediate value that was not significantly different from either the wild type or the mutant. The lack of complete complementation might be due to a fitness reduction caused by the complementing vector.

To evaluate the ability of K1317 to cause disease on susceptible tomato cv. Bonny Best, we performed a naturalistic soil soak assay (Tans-Kersten et al. 2001), inoculating unwounded tomato plants with suspensions of wild-type or K1317 strains. Like the wild-type, K1317 killed all plants by 14 days postinoculation (dpi) (Fig. 4). However, plants inoculated with K1317 showed a slight but significant delay of bacterial wilt symptom onset on days 6 and 7 postinoculation.

\section{R. solanacearum K1317 has reduced ability}

to kill host plants that overproduce hydrogen peroxide.

To determine whether increased plant-derived ROS can hinder $R$. solanacearum disease development, we infused $R$. solanacearum cells into the leaves of susceptible tobacco plants (cv. Petit Havana SR1) and a transgenic derivative with silenced leaf catalase 1 gene, which overproduces hydrogen peroxide (Chamnongpol et al. 1996). Leaves of the transgenic plants showed less necrosis and leaf tissue collapse than the leaves of the parental line at $48 \mathrm{~h}$ after inoculation (data not shown), and $R$. solanacearum cell numbers were lower in the catalase 1 -

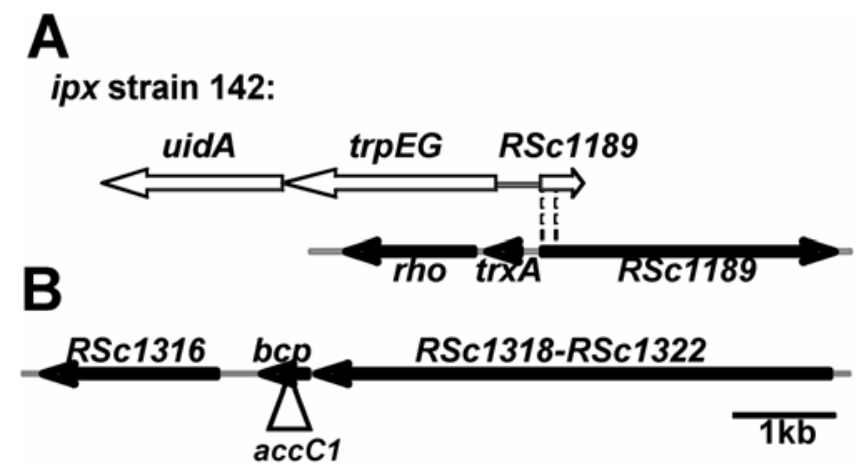

Fig. 1. Genomic regions of Ralstonia solanacearum GMI1000. A, Genomic context of in vivo expression technology (IVET) fusion in planta-expressed (ipx) 142. Arrows indicate the direction of transcription: white arrows are open reading frames (ORFs) originating from the IVET plasmid and black arrows are ORFs from GMI1000 genome. Dotted lines indicate the location of the IVET fusion in the $R$. solanacearum genome. RSc1189 encodes a protein of unknown function, $\operatorname{tr} x A$ encodes thioredoxin I, rho encodes a Rho transcriptional termination factor, $\operatorname{trp} E G$ encodes anthranilate synthase, and uidA encodes the $\beta$-glucuronidase reporter gene. B, Mutagenesis strategy for $b c p$ (RSc1317). Downstream of the $b c p$ ORF is RSc1316 (unknown function) and upstream are genes RSc1318 to RSc1322, which are predicted to encode proteins involved in lipopolysaccharide metabolism, and which may form an operon. The $b c p$ gene was mutated by introduction of a gentamicin resistance gene cassette (aacC1, triangle) into a unique restriction site. These genomic regions are colinear in $R$. solanacearum UW551.

Table 2. Ralstonia solanacearum in planta-expressed (ipx) genes that were also upregulated by hydrogen peroxide in culture ${ }^{\text {a }}$

\begin{tabular}{|c|c|c|c|}
\hline \multirow[b]{2}{*}{ ipx Strain $^{b}$} & \multicolumn{2}{|c|}{ Gene number } & \multirow[b]{2}{*}{ Predicted protein (gene name) } \\
\hline & GMI1000 & UW551 & \\
\hline 6 & $\mathrm{RSc} 0015$ & RRSL02946 & Conserved hypothetical protein \\
\hline 7 & $\mathrm{RSc0086}$ & RRSL04380 & Conserved hypothetical protein; GST superfamily \\
\hline 18 & RSc3367 & RRSL00854 & Hypothetical protein \\
\hline 19 & RSc3389 & RRSL04168 & Hypothetical protein \\
\hline 52 & RSp0536 & Absent & Transmembrane sugar-proton symporter \\
\hline 65 & RSc1317 & RRSL00135 & Peroxidase $(b c p)$ \\
\hline 71 & RSp1530 & RRSL04639 & L-ascorbate oxidase \\
\hline 74 & $\mathrm{RSc} 0076$ & RRSL02003 & Proline-rich signal peptide \\
\hline 81 & $\mathrm{RSc} 3030$ & RRSL00873 & Signal peptide protein \\
\hline 88 & $\mathrm{RSc} 0280$ & RRSL01667 & Transcription regulator \\
\hline 112 & $\mathrm{RSc} 0378$ & RRSL03283 & Anthranilate phosphoribosyl transferase \\
\hline 115 & RSc1126 & RRSL01951 & CTP synthase \\
\hline 119 & RSc2095 & RRSL01253 & Xanthine dehydrogenase \\
\hline 142 & RSc1189 & RRSL00301 & Thioredoxin $(\operatorname{tr} x A)^{\mathrm{c}}$ \\
\hline
\end{tabular}

\footnotetext{
a Annotation and gene number according to GMI1000 and UW551 genomes (Gabriel et al. 2006; Salanoubat et al. 2002).

${ }^{\mathrm{b}}$ From Brown and Allen (2004).

c Initially described as backwards.
} 
silenced plants compared with those in the parental line (Fig. 5A). However, there was no measurable difference in population size between K60 and K1317 on either plant host (data not shown). Soil-soak virulence assays on these tobacco plants revealed that, by $10 \mathrm{dpi}$, both strains killed significantly more wild-type tobacco plants than the catalase 1 -silenced derivative. Moreover, K1317 killed significantly fewer hydrogen peroxide-overproducing plants than K60.

\section{DISCUSSION}

As part of the host defense response, plants produce an oxidative burst. This burst occurs in two phases depending on the ability of the microbe to evade or suppress its host's defenses (Espinosa and Alfano 2004). Some successful pathogens only encounter the first, transient phase of the oxidative burst. However, other microbes experience the prolonged phase that induces the host defense response and resistance (Lamb and Dixon 1997). Some bacterial plant pathogens differentially express oxidative stress response genes during midphase pathogenicity (Okinaka et al. 2002; Rediers et al. 2005; Tamir-Ariel et al. 2007), suggesting that they are exposed to a prolonged phase of the oxidative burst or continuous oxidative stress during host infection. E. amylovora, the causal agent of fire blight, has been shown to induce a sustained phase of the oxidative burst during pear leaf infection (Venisse et al. 2001). Thus, successful plant pathogens must possess efficient oxidative stress defense mechanisms in order to infect, spread in their hosts, and cause disease.

An IVET screen of $R$. solanacearum identified 153 genes that are induced during midphase pathogenicity; approximately $10 \%$ of these genes have predicted functions in stress defense (Brown and Allen 2004). These results suggest that this pathogen confronts a stressful environment during tomato patho-
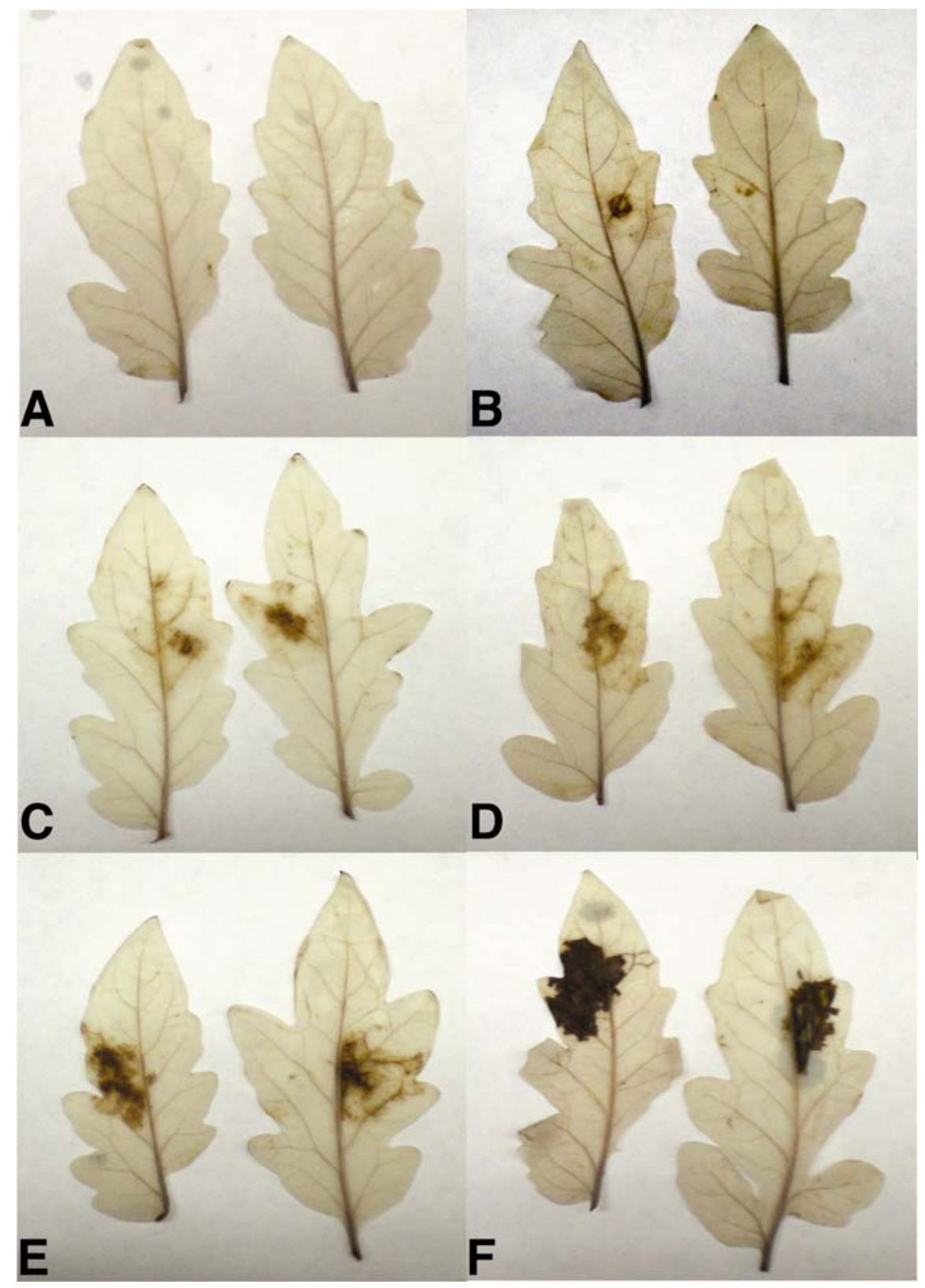

Fig. 2. Generation of hydrogen peroxide in susceptible tomato leaves infected with Ralstonia solanacearum and visualized by 3,3-diaminobenzidine (DAB) staining after $24 \mathrm{~h}$. Tomato leaves (cv. Bonny Best) were infused as follows: A, untreated control; B, water-inoculated control; C, leaves inoculated with $R$. solanacearum cells at $5 \times 10^{6} \mathrm{CFU} / \mathrm{ml} ; \mathbf{D}, 1 \times 10^{7} \mathrm{CFU} / \mathrm{ml} ; \mathbf{E}, 5 \times 10^{7} \mathrm{CFU} / \mathrm{ml} ; \mathbf{F}, 1 \times 10^{9} \mathrm{CFU} / \mathrm{ml}$. This experiment was performed three times independently with similar results; representative results are shown. 
genesis. Indeed, mutagenesis of in planta-expressed multidrug efflux pumps in $R$. solanacearum significantly reduced virulence (Brown et al. 2007), providing direct evidence that, during disease, $R$. solanacearum encounters antimicrobial compounds, probably derived from the host defense response. Genes predicted to encode elements of the oxidative stress response were among those identified in the IVET screen (Brown and Allen 2004), suggesting that ROS are among the stresses that $R$. solanacearum must overcome to succeed as a pathogen.

Bioinformatic analyses of two $R$. solanacearum genomes offered further evidence that this pathogen is exposed to ROS during its life cycle. Approximately 15 redundant ROS-scavenging enzymes were identified in two $R$. solanacearum genomes (Table 1), suggesting that $R$. solanacearum is well adapted for oxidative environments. One of the predicted peroxidases, $b c p$, was previously identified in the IVET screen (Brown and Allen 2004).

If $R$. solanacearum encounters oxidative stress during host infection, it seemed likely that some plant-induced genes also respond to oxidative stress. Fourteen of the IVET-identified genes $(9 \%)$ were induced by hydrogen peroxide in culture (Table 2). This result suggests that these genes are part of an oxidative stress response that is induced while in the host. Predicted functions of several genes induced by hydrogen peroxide sug-

Table 3. Ralstonia solanacearum cell populations in tomato leaves infiltrated and stained for hydrogen peroxide ${ }^{\mathrm{a}}$

\begin{tabular}{|c|c|c|}
\hline \multirow[b]{2}{*}{ Initial inoculum (CFU/ml) } & \multicolumn{2}{|c|}{$\begin{array}{l}R \text {. solanacearum populations } 24 \mathrm{~h} \text { after } \\
\text { inoculation }\left(\mathrm{CFU} / \mathrm{cm}^{2} \text { of leaf) }\right.\end{array}$} \\
\hline & Bonny Best & Hawaii 7996 \\
\hline $5 \times 10^{5}$ & $5.2 \times 10^{6}$ & $1.5 \times 10^{7}$ \\
\hline $1 \times 10^{6}$ & $1.1 \times 10^{7}$ & $2.6 \times 10^{7}$ \\
\hline $5 \times 10^{6}$ & $4.6 \times 10^{7}$ & $3.9 \times 10^{7}$ \\
\hline $1 \times 10^{7}$ & $1.2 \times 10^{8}$ & $1.4 \times 10^{8}$ \\
\hline $5 \times 10^{7}$ & $1.6 \times 10^{8}$ & $3.6 \times 10^{8}$ \\
\hline
\end{tabular}

${ }^{a}$ Results shown are representative of two assays with similar results.

${ }^{\text {b }}$ Population size at the time of $\mathrm{H}_{2} \mathrm{O}_{2}$ stain.

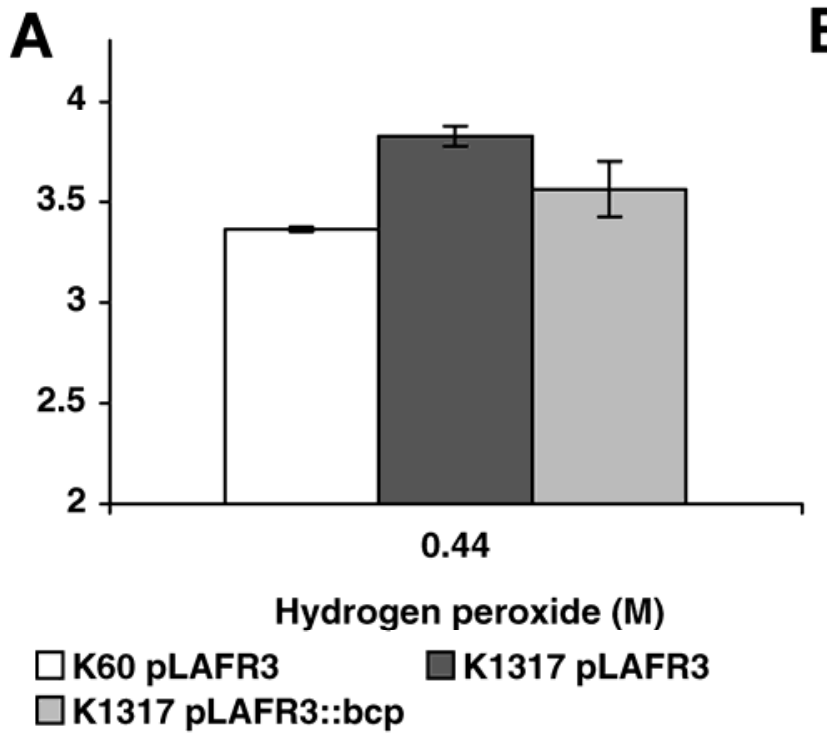

gest a role in the oxidative stress response: pyrimidine synthesis (ipx 115) for DNA damage repair; metabolism of the antioxidant ascorbate (ipx 71); amino acid biosynthesis (ipx 112), which might indicate a role in de novo protein synthesis or protein damage repair; and xanthine dehydrogenase (ipx 119), which is involved in purine metabolism resulting in the generation of the antioxidant uric acid (or urate) (Becker 1993). Thioredoxins (ipx 142) maintain the reduced state of intracellular disulfide bonds, including those in peroxidases (Imlay

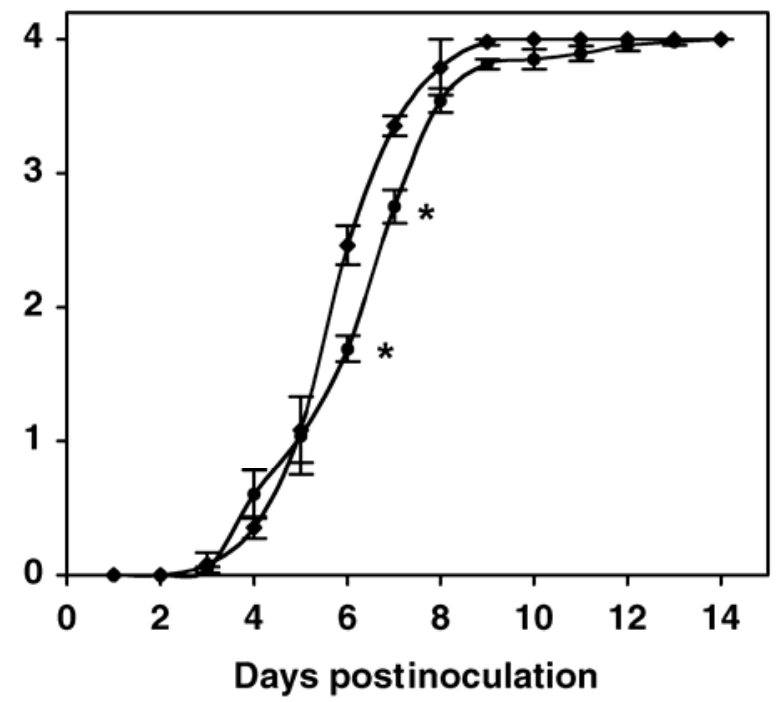

Fig. 4. Disease progress curves of Ralstonia solanacearum strains on susceptible tomato plants. Bacterial suspensions of $R$. solanacearum K60 (diamonds) and K1317 (circles) were poured into pots containing unwounded 15-day-old tomato plants. Disease symptoms were evaluated daily for 14 days using a 0-to-4 disease index. Results shown are the average of three independent experiments; bars indicate standard error of the mean. Inoculum ranged from $3.9 \times 10^{7}$ to $5.7 \times 10^{7} \mathrm{CFU} / \mathrm{g}$ of soil. Asterisks indicate days where wild-type and K1317 strains were significantly different according to analysis of variance $(P<0.05)$.

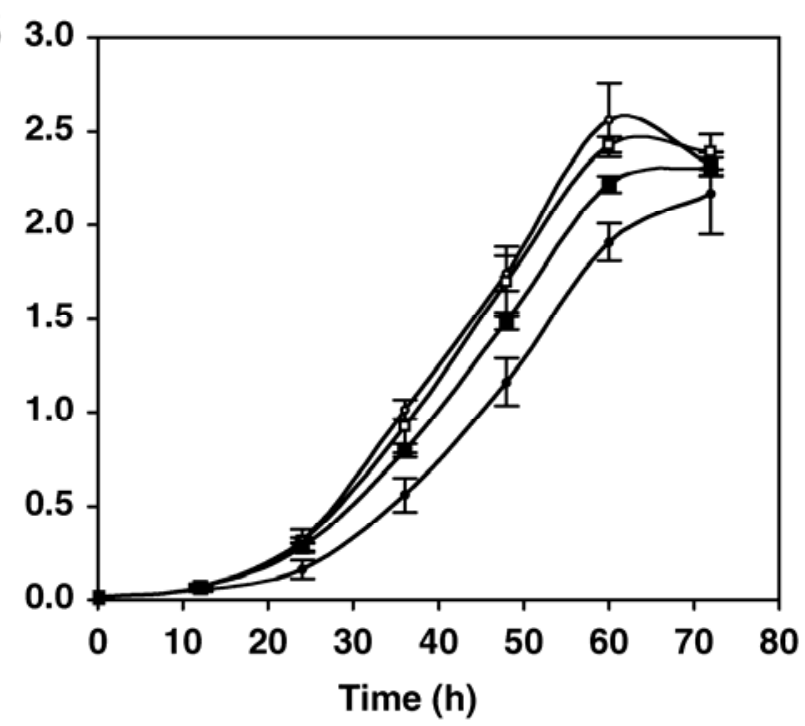

Fig. 3. Ralstonia solanacearum strain sensitivity to reactive oxygen species. A, Disk inhibition assay. A bacterial suspension was added to warm top agar and poured over agar plates. A filter disk containing $10 \mu \mathrm{l}$ of hydrogen peroxide was placed in the center of the plate and incubated at $28^{\circ} \mathrm{C}$ for $24 \mathrm{~h}$. Initial inoculum in top agar: $R$. solanacearum K60/pLAFR3 (wild type), $1.61 \times 10^{7} \mathrm{CFU} / \mathrm{ml}$; K1317/pLAFR3, $1.19 \times 10^{7} \mathrm{CFU} / \mathrm{ml}$; K1317/pLAFR3::bcp, 6.25 × $10^{6} \mathrm{CFU} / \mathrm{ml}$. Results are the average of two independent experiments with four measurements per experiment; bars represent standard error of the mean. B, Growth curve of $R$. solanacearum strains in the presence of $1 \mu \mathrm{M}$ paraquat. $R$. solanacearum K60 (wild-type, squares) and $\mathrm{K} 1317$ (bcp mutant; circles) were grown in minimal medium broth in the presence (filled symbols) or absence (empty symbols) of $1 \mu \mathrm{M}$ paraquat (PQ). Results are the average of three independent growth curves, each with three flasks per treatment; bars represent standard error of the mean. Columns with different letters above are significantly different according to the Fisher least significant difference test $(P<0.05)$. 
2008). Genes with predicted functions similar to those in Table 2 have also been identified in IVET screens of other pathogenic and beneficial bacteria (Rediers et al. 2005), suggesting that microbes associated with eukaryotes are exposed to ROS during interaction with their hosts.

The indirect evidence described above implies that $R$. solanacearum encounters oxidative stress during tomato infection. To more directly determine whether this pathogen is exposed to ROS during tomato pathogenesis, we visualized hydrogen peroxide in tomato leaves during infection with a specific stain (Fig. 2). Hydrogen peroxide was present in infected tomato leaves and, although the stain was not quantitative, its concentration appeared to increase as disease progressed and as the pathogen populations grew. This is evidence that $R$. solanacearum is exposed to ROS during mid- to end-stage pathogenesis and suggests that this pathogen might be experiencing the sustained phase of the host-derived oxidative burst that is usually associated with incompatible interactions or a continuous oxidative burst. This finding also suggests that the redundant ROS-scavenging enzymes and the additional IVET-identified genes that are also induced by hydrogen peroxide help $R$. solanacearum overcome this oxidative stress to successfully infect and persist in its hosts, and cause disease.

The similar levels of hydrogen peroxide in wilt-susceptible and wilt-tolerant tomato leaves in response to $R$. solanacearum suggest that the resistance in the tolerant line, Hawaii 7996, is not the result of a heightened oxidative burst. This result is consistent with the finding that $R$. solanacearum readily forms latent infections in Hawaii 7996 (Grimault et al. 1994). However, it is possible that, during natural disease progress, when $R$. solanacearum colonizes the xylem tissue before spreading out into leaves, this bacterium encounters different oxidative conditions (see below). In addition, given the qualitative nature of hydrogen peroxide detection by $\mathrm{DAB}$, it is possible that small differences in hydrogen peroxide concentrations among the different tomato lines would not have been observed.

To test the contribution of $b c p$ to the oxidative stress response and virulence of $R$. solanacearum, we created a $b c p$ mutant, K1317 (Fig. 1A). In Escherichia coli, bcp encodes a thioredoxin-dependent peroxidase of the TSA/AhpC family that is necessary for normal growth in the presence of hydrogen peroxide (Jeong et al. 2000). Bcp homologues are necessary for host colonization in the animal pathogens Helicobacter pylori and Brucella melitensis (Wang et al. 2005; Zygmunt et al. 2006). In addition, $b c p$ homologues were identified in IVET screens of other plant-associated bacteria (Hammad et al. 2001; Rediers et al. 2003), suggesting that $b c p$ is generally important in host-microbe interactions. The $R$. solanacearum bcp gene (ipx 65) is 20-fold induced in planta (Brown and Allen 2004), and was also upregulated in rich media in the presence of hydrogen peroxide (Table 2). Bcp was necessary for $R$. solanacearum ROS detoxification in culture, confirming its role in the oxidative stress response of $R$. solanacearum. The combination of bioinformatic analysis and the hypersensitivity of the $b c p$ mutant to ROS in culture suggest that Bcp encodes a peroxidase in $R$. solanacearum (Fig. 3). However, this protein played a minor role in tomato virulence (Fig. 4), possibly because of compensation from other predicted oxidative stress response genes in $R$. solanacearum (Tables 1 and 2).

$R$. solanacearum was affected in growth and disease development in tobacco plants that overproduce hydrogen peroxide (Fig. 5), suggesting that host-produced ROS can limit pathogen success. However, because it is a very successful pathogen, $R$. solanacearum can evidently overcome the lower concentrations of ROS present in natural hosts. K1317 grew as well as its wild-type parent when cells were directly infused into tobacco leaves regardless of the tobacco host used (data not shown), suggesting that, under these artificial conditions, Bcp does not make a large contribution to ROS detoxification. In contrast, the hydrogen peroxide-overproducing plants were more resistant to K1317 than to the wildtype in a naturalistic soil-soak assay that required bacteria to infect plants through unwounded roots (Fig. 5B). These results indicate that plant-derived ROS can inhibit $R$. solanacearum growth in planta and, further, that Bcp is necessary for detoxification of plant-derived hydrogen peroxide. In addition, these results suggest that the oxidative stress encountered during natural disease progress by $R$. solanacearum is different from and possibly greater than that experienced following artificial leaf infusion.
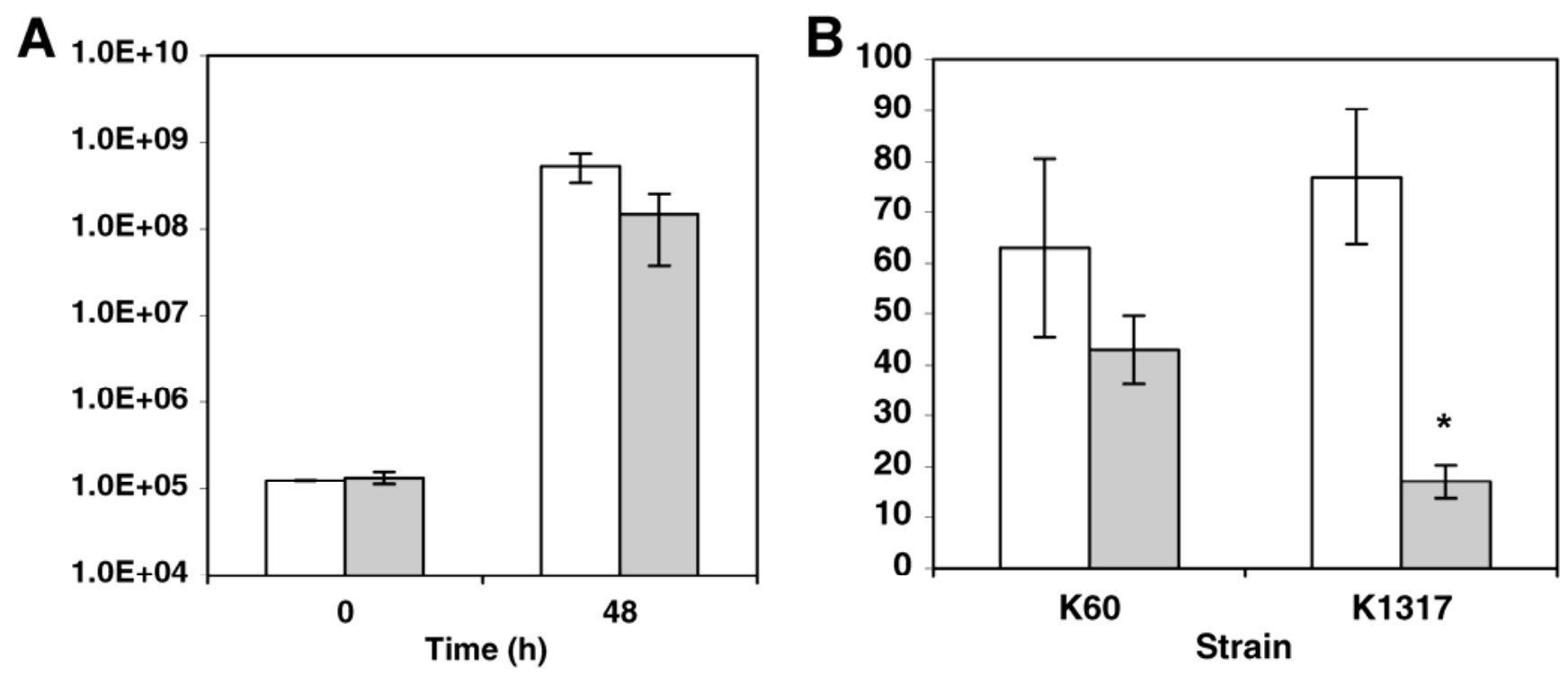

Fig. 5. Behavior of Ralstonia solanacearum K60 in bacterial wilt-susceptible tobacco cv. Petit Havana SRI (white bars) and a transgenic derivative that overproduces hydrogen peroxide CatAS1 (gray bars). A, $R$. solanacearum cell populations in leaves were quantified via dilution plating. Data represent mean of two independent assays; bars represent standard error of the mean. B, Percent dead plants 10 days postinoculation. Inoculum ranged from $3.3 \times 10^{7}$ to $1 \times 10^{8}$ $\mathrm{CFU} / \mathrm{g}$ of soil. Results shown are the average of three independent experiments; bars represent standard error of the mean. Asterisk indicates treatment that was statistically different according to analysis of variance $(P<0.05)$. 
The slight delay in disease onset on susceptible tomato plants inoculated with K1317 on days 6 and 7 might coincide with a delayed host defense response. This late oxidative burst would coincide with maximum $R$. solanacearum populations in the plant and is consistent with the detection of hydrogen peroxide in tomato leaves, where the stain intensity increased with cell populations (Fig. 2). In addition, preliminary results indicate that $R$. solanacearum induces maximum host defense gene expression 7 to 8 days after soil-soak inoculation of susceptible tomato plants (A. Milling and C. Allen, unpublished results), significantly later than it occurred during previously studied infections that result in resistance (Lamb and Dixon 1997). Similarly, a Xanthomonas campestris pv. malvacearum infection leading to disease resulted in a delayed and less intense oxidative burst than an infection leading to resistance (Jalloul et al. 2002). Together, these results suggest that $R$. solanacearum is able to evade or suppress host defenses until it reaches high populations within the host, by which time any host response would be ineffectual.

Together, these findings demonstrate that $R$. solanacearum encounters oxidative stress during plant pathogenesis, and that an effective bacterial oxidative stress response is necessary and important for successful host infection. In addition, these direct and indirect results collectively suggest that the concentrations of ROS experienced by this pathogen during disease may have direct antimicrobial activity. Although Bcp was necessary for ROS detoxification in culture, a $b c p$ mutant had only a minor reduction in virulence on tomato, very likely because the pathogen's other peroxidases can partially compensate for the loss of Bcp. This result highlights the limitations of a singlegene mutagenesis approach and reinforces our view that complex molecular interactions give rise to bacterial wilt disease. Given that successful microbial-host interactions result from the interaction of multiple gene products differentially expressed at different stages of the infection, it is not surprising that the bcp mutant has a small virulence defect. Consistent with our results, several genes identified in IVET screens of other plantpathogenic bacteria also don't contribute measurably to virulence (Tamir-Ariel et al. 2007), including some genes identified in $R$. solanacearum's IVET screen (Gonzalez et al. 2007). Because $R$. solanacearum possesses multiple and redundant genes involved in the oxidative stress response, mutagenesis of $\operatorname{oxy} R$, the only apparent regulator of $R$. solanacearum's oxidative stress response, would shed light on the role of the oxidative stress response during host colonization and disease development of $R$. solanacearum.

\section{MATERIALS AND METHODS}

\section{Bacterial strains and growth conditions.}

The bacterial strains and plasmids used in this study are listed in Table 4. E. coli strains were grown in Luria-Bertani medium (Miller 1992 ) at $37^{\circ} \mathrm{C}$. All $R$. solanacearum strains in this study were derived from wild-type biovar 1 phylotype II sequevar 7 strain K60 (Kelman 1954). R. solanacearum strains were grown in CPG broth (Hendrick and Sequeira 1984) or CPG solid medium with $0.05 \%$ (wt/vol) tetrazolium chloride (Kelman 1954). Antibiotics were added to cultures at the following concentrations when necessary: kanamycin at 25 $\mu \mathrm{g} / \mathrm{ml}$, gentamicin at $12.5 \mu \mathrm{g} / \mathrm{ml}$, and tetracycline at $15 \mu \mathrm{g} / \mathrm{ml}$. Growth curves were performed in minimal BMM (Boucher et al. 1985) supplemented with $0.2 \%$ (wt/vol) glucose as previously described (Gonzalez and Allen 2003). Growth curves to determine the effect of paraquat (Ultra Scientific, N. Kingstown, RI, U.S.A.) on growth of strain K1317 were performed in BMM supplemented with $0.2 \%$ malate buffered with 50 $\mathrm{mM}$ morpholineethanesulfonic acid.

In planta growth of $R$. solanacearum strains was measured by quantifying bacterial multiplication in tobacco leaves (Nicotiana tabacum cv. Bottom Special or N. tabacum cv. Petit Havana SRI and its catalase 1 -silenced derivative Cat1AS) (Chamnongpol et al. 1996) as previously described (TansKersten et al. 2001).

\section{DNA manipulations.}

The isolation of plasmid, cosmid, and genomic DNA as well as polymerase chain reaction (PCR), cloning, and Southern hybridization were carried out by standard protocols (Ausubel et al. 1998). Competent cells of E. coli and $R$. solanacearum were created as previously described (Allen et al. 1991). Unless otherwise noted, chemical reagents were purchased from Sigma-Aldrich (St. Louis) and molecular biology reagents and kits were purchased from Promega Corp. (Madison, WI, U.S.A.).

Table 4. Strains and plasmids used in this study

\begin{tabular}{|c|c|c|}
\hline Strain or plasmid & Relevant characteristics $^{\mathbf{a}}$ & Reference or source \\
\hline \multicolumn{3}{|l|}{ Escherichia coli strain } \\
\hline DH5 $\alpha$ & $\mathrm{F}^{-}$endA1 relA $\phi 80$ lacZ4 supE44 thi-1 recA1 gyrA96 & Hanahan 1983 \\
\hline HB101 & $\mathrm{F}^{-}$, thi-1 hsdS20 supE44 recA13 ara-14 leuB6 proA2 lacY1 galK2 rpsL20 xyl-5, mtl-1 & Boyer and Roulland-Dussoix 1969 \\
\hline \multicolumn{3}{|c|}{ Ralstonia solanacearum strains } \\
\hline K60 & Wild type; phylotype II, biovar 1, sequevar 7 & Kelman 1954 \\
\hline ipx strains & $\mathrm{K} 60 \Delta$ trpEG; diverse plant-induced promoters: $\operatorname{trp} E G ; \mathrm{Km}^{\mathrm{r}}$ & Brown and Allen 2004 \\
\hline K1317 & $\mathrm{K} 60$ bcp::aacC1; $\mathrm{Gm}^{\mathrm{r}}$ & This study \\
\hline PpilA-forward & $\mathrm{K} 60$ trpEG $\Delta ;$ pilA promoter (forward orientation) ::trpEG; $\mathrm{Km}^{\mathrm{r}}$ & Brown and Allen 2004 \\
\hline PpilA-reverse & $\mathrm{K} 60$ trpEG 4 ; pilA promoter (reverse orientation) $:: \operatorname{trpEG} ; \mathrm{Km}^{\mathrm{r}}$ & Brown and Allen 2004 \\
\hline \multicolumn{3}{|c|}{ W } \\
\hline pSTblue-1 & $\mathrm{Km}^{\mathrm{r}} \mathrm{Ap}{ }^{\mathrm{r}}$ & Novagen \\
\hline pLAFR3 & $\mathrm{Tc}^{\mathrm{r}}$ & Staskawicz et al. 1987 \\
\hline pUCGM & $\mathrm{Gm}^{\mathrm{r}} \mathrm{Ap}^{\mathrm{r}}$ & Schweizer 1993 \\
\hline pCR-Blunt II-Topo & $\mathrm{Km}^{\mathrm{r}} \mathrm{Zeo}^{\mathrm{r}}$ & Invitrogen \\
\hline pVO155 & Promoter probe plasmid with promoterless uidA gene; $\mathrm{Km}^{\mathrm{r}}$ & Oke and Long 1999 \\
\hline pRK600 & pRK2013 ntp::Tn9; $\mathrm{Cm}^{\mathrm{r}}$ & Finan et al. 1986 \\
\hline pSJYoT & oriT from pVO155 cloned into pSTBlue- $1 ; \mathrm{Km}^{\mathrm{r}} \mathrm{Ap}^{\mathrm{r}}$ & J. Yao, unpublished results \\
\hline pSTbcp & 900-bp insert containing $b c p$ in pSTBlue- $1 ; \mathrm{Km}^{\mathrm{r}} \mathrm{Ap}^{\mathrm{r}}$ & This study \\
\hline pTOPObcp & 900-bp insert containing $b c p$ in pCR-Blunt II-Topo & This study \\
\hline pLAFR3bcp & 900-bp EcoRI fragment from pTOPObcp cloned into pLAFR3; $\mathrm{Tc}^{\mathrm{r}}$ & This study \\
\hline pSTbcp::aacC1 & pSTbcp with 850-bp Gm ${ }^{r}$ cassette insertion from pUCGM: $\mathrm{Km}^{\mathrm{r}} \mathrm{Ap}^{\mathrm{r}} \mathrm{Gm}^{\mathrm{r}}$ & This study \\
\hline pSJYoTTbcp::aacCl & 1.8-kb EcoRI fragment from pSRbcp::aacCl cloned into pSJYoT; $\mathrm{Km}^{\mathrm{r}} \mathrm{Ap}^{\mathrm{r}} \mathrm{Gm}^{\mathrm{r}}$ & This study \\
\hline
\end{tabular}

${ }^{\mathrm{a}} \mathrm{Ap}^{\mathrm{r}}, \mathrm{Km}^{\mathrm{r}}, \mathrm{Gm}^{\mathrm{r}}, \mathrm{Tc}^{\mathrm{r}}$, and $\mathrm{Zeo}^{\mathrm{r}}$ indicate resistance to ampicillin, kanamycin, gentamicin ,tetracycline, and zeocin, respectively. 
Oligonucleotides and sequence analysis.

DNA and protein sequences were analyzed using Biology Workbench, National Center for Biotechnology Information Blast (Altschul et al. 1997), NEB Cutter, and the genomic databases of phylotype II sequevar 1 (race 3, biovar 2) $R$. solanacearum UW551 and phylotype I sequevar 12 strain GMI1000. Oligonucleotides were purchased from Qiagen Operon (Alameda, CA, U.S.A.) or Integrated DNA Technologies (Coralville, IA, U.S.A.). DNA sequencing was performed at the University of Wisconsin Biotechnology Center (Madison).

\section{Construction of $b c p$ mutant K1317.}

A 954-bp DNA fragment containing the putative $b c p$ ORF was amplified by PCR using primers 5'CATCCGTATATCCC GAGCAT3' and 5'CGGATTTCGTACTCATCGGT3' designed from the GMI1000 genomic sequence. The resulting fragment was AT-cloned into pSTBlue-1, creating pSTbcp, and sequenced. The gentamicin resistance-encoding cassette aacCI from pUCGM was introduced into the unique StuI site of the bcp ORF, creating pSTbcp::Gent. The mutant allele was introduced into $R$. solanacearum K60 through triparental mating using the helper plasmid pRK600 in E. coli HB101 and the donor plasmid pSJYoT carrying the bcp::aacC1 EcoRI fragment from pSTbcp::aacCI. Allelic replacement of the $b c p$ gene in the $R$. solanacearum chromosome was confirmed by PCR and Southern blot analysis (data not shown). The confirmed bcp mutant was called K1317.

\section{Complementation of K1317.}

Primers 5'CATCCGTATATCCCGAGCAT3' and 5'CGGAT TTCGTACTCATCGGT3' were used to amplify the approximately 900-bp fragment containing the $b c p$ gene with PfuUltra DNA polymerase (Stratagene, La Jolla, CA, U.S.A.), and the resulting product was cloned into pCR-Blunt II-TOPO vector (Invitrogen, Carlsbad, CA, U.S.A.) to create pTOPO-bcp. Using EcoRI sites, the 954-bp fragment was subcloned into the low copy-number vector pLAFR3 (Staskawicz et al. 1987). For trans complementation, electroporation was used to introduce pLAFR3 into wild-type $R$. solanacearum and K1317, and pLAFR3-bcp into K1317.

\section{$\beta$-Glucuronidase activity filter assay.}

Each of the 153 ipx fusion strains identified in the previous $R$. solanacearum IVET screen contains a transcriptional fusion to the $\beta$-glucuronidase (uidA) reporter gene (Brown and Allen 2004). These 153 fusion strains were spotted onto unmodified CPG plates and GPG plates containing $276 \mu \mathrm{M} \mathrm{H}_{2} \mathrm{O}_{2}$. After overnight incubation at room temperature, the resulting colonies were lifted using Whatman no. 1 filters. To determine gene expression, we measured $\beta$-glucuronidase activity via a colorimetric assay as previously described (Brown and Allen 2004). White colonies were considered to have little or no gene expression; blue colonies were considered to carry fusions induced by hydrogen peroxide. Those that were blue on CPG with $\mathrm{H}_{2} \mathrm{O}_{2}$ but remained white on plain CPG were selected. Fusions carrying the constitutively expressed pilA promoter cloned in the forward and backward orientation to the uidA gene were used as positive and negative controls for $\beta$-glucuronidase activity detection and relative color intensity, respectively.

\section{Hydrogen peroxide detection in planta.}

Hydrogen peroxide production in plant host tissue was detected with DAB stain, which forms a brown precipitate in the presence of hydrogen peroxide. Four tomato leaves of the wiltsusceptible cv. Bonny Best and the wilt-tolerant tomato line Hawaii 7996 (Thurston 1976) were infused with water or with different concentrations of $R$. solanacearum cells. At $24 \mathrm{~h}$ postinoculation, three leaves were cut at the petiole and placed in DAB solution ( $\mathrm{pH} \mathrm{3.8)}$ at $1 \mu \mathrm{g} / \mathrm{ml}$ for $8 \mathrm{~h}$ under light at room temperature (Giovanini et al. 2006). Leaves were then bleached in boiling $95 \%$ ethanol for 10 min and stored in $70 \%$ ethanol. The fourth leaf was used to quantify the $R$. solanacearum populations within the leaf. Three samples were taken per leaf, pooled, ground, and dilution plated in triplicate.

\section{Disk growth inhibition assay.}

Overnight broth cultures of $R$. solanacearum were collected by centrifugation and resuspended in sterile distilled water. Optical density was adjusted to an optical density at $600 \mathrm{~nm}$ of 0.1 , roughly $1 \times 10^{8} \mathrm{CFU} / \mathrm{ml}$, and $100 \mu \mathrm{l}$ of the cell suspension was added to warm BMM top agar and poured over BMM agar plates with $0.2 \%$ malate buffered with $50 \mathrm{mM}$ MES as sole carbon source. Once the top agar solidified, a Whatman no. 1 filter disk containing $10 \mu \mathrm{l}$ of $0.44 \mathrm{M}$ hydrogen peroxide was placed in the center of the plate and incubated at $28^{\circ} \mathrm{C}$ for $24 \mathrm{~h}$. The cell suspension $(100 \mu \mathrm{l})$ was dilution plated to determine exact initial cell numbers. The zone of growth inhibition around each disk was measured twice at $90^{\circ}$ angles.

\section{Virulence assays.}

Susceptible tomato plants cv. Bonny Best, tobacco plants cv. Petit Havana SRI, and a transgenic derivative of Petit Havana SRI engineered to overproduce hydrogen peroxide (Chamnongpol et al. 1996) were used in a naturalistic soilsoak assay as previously described (Tans-Kersten et al. 1998). Briefly, a suspension of bacteria was poured over the potting mix of 15-day-old tomato plants. Plants were kept in a growth chamber with 12-h day-and-night cycles at $28^{\circ} \mathrm{C}$. Disease symptoms were evaluated daily for 14 days using a 0 -to- 4 disease index. The assay was performed in triplicate in both hosts, with 16 plants per treatment in the tomato assays and 10 plants per treatment for the tobacco assays.

\section{Statistical analysis.}

Analysis of variance analysis was performed with Minitab Statistical Software (Minitab, Inc., State College, PA, U.S.A.).

\section{ACKNOWLEDGMENTS}

We thank R. Shah (Louisiana State University) for valuable technical assistance and D. Inze (Ghent University) for the generous gift of catalase 1-silenced tobacco plant seeds. This research was supported by United States Department of Agriculture National Research Institute Cooperative State Research Education and Extension Service grant number 200755605-17843 and by the University of Wisconsin-Madison College of Agricultural and Life Sciences.

\section{LITERATURE CITED}

Allen, C., Huang, Y., and Sequeira, L. 1991. Cloning of genes affecting polygalacturonase production in Pseudomonas solanacearum. Mol. Plant-Microbe Interact. 4:147-154.

Altschul, S. F., Madden, T. L., Schaffer, A. A., Zhang, J. H., Zhang, Z., Miller, W., and Lipman, D. J. 1997. Gapped BLAST and PSI-BLAST: A new generation of protein database search programs. Nucleic Acids Res. 25 (17):3389-3402.

Apel, K., and Hirt, H. 2004. Reactive oxygen species: Metabolism, oxidative stress, and signal transduction. Annu. Rev. Plant. Biol. 55 (1):373399.

Arlat, M., Gough, C. L., Zischek, C., Barberis, P. A., Trigalet, A., and Boucher, C. A. 1992. Transcriptional organization and expression of the large hrp gene cluster of Pseudomonas solanacearum. Mol. Plant-Microbe Interact. 5 (2):187-93.

Ausubel, F. M., Brent, R., Kingston, R., Moore, D., Seidman, J., Smith, J., and Struhl, K. 1998. Current Protocols in Molecular Biology, Vol. 1-4. John Wiley \& Sons, Inc., New York

Becker, B. F. 1993. Towards the physiological function of uric acid. Free. Radic. Biol. Med. 14:615-31. 
Boucher, C., Barberis, P., Trigalet, A., and Demery, D. 1985. Transposon mutagenesis of Pseudomonas solanacearum: Isolation of Tn5-induced avirulent mutants. J. Gen. Microbiol. 131:2449-2457.

Boyer, H. W., and Roulland-Dussoix, D. 1969. A complementation analysis of the restriction and modification of DNA in Escherichia coli. J. Mol. Biol. 41:459-72.

Brown, D. G., and Allen, C. 2004. Ralstonia solanacearum genes induced during growth in tomato: An inside view of bacterial wilt. Mol. Microbiol. 53:1641-1660.

Brown, D. G., Swanson, J. K., and Allen, C. 2007. Two host-induced Ralstonia solanacearum genes, acrA and $\operatorname{din} F$, encode multidrug efflux pumps and contribute to bacterial wilt virulence. Appl. Environ. Microbiol. 73:2777-2786.

Chamnongpol, S., Willekens, H., Langebartels, C., VanMontagu, M., Inze, D., and VanCamp, W. 1996. Transgenic tobacco with a reduced catalase activity develops necrotic lesions and induces pathogenesis-related expression under high light. Plant J. 10:491-503.

Denny, T., and Baek, S. 1991. Generic evidence that extracellular polysaccharide is a virulence factor of Pseudomonas solanacearum. Mol. Plant-Microbe Interact. 4:198-206.

Espinosa, A., and Alfano, J. 2004. Disabling surveillance: Bacterial type III secretion system effectors that suppress innate immunity. Cell Microbiol. 6:1027-1040.

Finan, T. M., Kunkel, B., De Vos, G. F., and Signer, E. R. 1986. Second symbiotic megaplasmid in Rhizobium meliloti carrying exopolysaccharide and thiamine synthesis genes. J. Bacteriol. 167:66-72.

Flavier, A. B., Clough, S. J., Schell, M. A., and Denny, T. P. 1997. Identification of 3-hydroxypalmitic acid methyl ester as a novel autoregulator controlling virulence in Ralstonia solanacearum. Mol. Microbiol. 26:251-259.

Gabriel, D., Allen, C., Schell, M., Denny, T., Greenberg, J., Duan, Y., Flores-Cruz, Z., Huang, Q., Clifford, J., Presting, G., González, E., Reddy, J., Elphinstone, J., Swanson, J., Yao, J., Mulholland, V., Liu, L. Farmerie, W., Patnaikuni, M., Balogh, B., Norman, D., Alvarez, A., Castillo, J., Jones, J., Saddler, G., Walunas, T., Zhukov, A., and Mikhailova, N. 2006. Identification of open reading frames unique to a select agent: Ralstonia solanacearum race 3 biovar 2. Mol. PlantMicrobe Interact. 19:69-79.

Giovanini, M. P., Puthoff, D. P., Nemacheck, J. A., Mlttapalli, O. Saltzmann, K. D., Ohm, H. W., Shukle, R. H., and Williams, C. 2006 Gene-for-gene defense of wheat against the Hessian Fly lacks a classical oxidative burst. Mol. Plant-Microbe Interact. 19:1023-1033.

Gonzalez, E. T., and Allen, C. 2003. Characterization of a Ralstonia solanacearum operon required for polygalacturonate degradation and uptake of galacturonic acid. Mol. Plant-Microbe Interact. 16:536-544.

Gonzalez, E. T., Brown, D. G., Swanson, J. K., and Allen, C. 2007. Using the Ralstonia solanacearum Tat secretome to identify bacterial wilt virulence factors. Appl. Environ. Microbiol. 73:3779-3786.

Grimault, V., Anais, G., and Prior, P. 1994. Distribution of Pseudomonas solanacearum in the stem tissues of tomato plants with different levels of resistance to bacterial wilt. Plant Pathol. 43:663-668.

Hammad, Y., Marechal, J., Cournoyer, B., Normand, P., and Domenach, A. M. 2001. Modification of the protein expression pattern induced in the nitrogen-fixing actinomycete Frankia sp. strain ACN14a-tsr by root exudates of its symbiotic host Alnus glutinosa and cloning of the sodF gene. Can. J. Microbiol. 47:541-547.

Hanahan, D. 1983. Studies on transformation of Escherichia coli with plasmids. J. Mol. Biol. 166:557-580.

Hassouni, M. E., Chambost, J. P., Expert, D., Van Gijsegem, F., and Barras, F. 1999. The minimal gene set member $m s r A$ encoding peptide methionine sulfoxide reductase, is a virulence determinant of the plan pathogen Erwinia chrysanthemi. Proc. Natl. Acad. Sci. U.S.A. 96:887892

Hayward, A. C. 1991. Biology and epidemiology of bacterial wilt caused by Pseudomonas solanacearum. Annu. Rev. Phytopathol. 29:65-87.

Hendrick, C. A., and Sequeira, L. 1984. Lipopolysaccharide-defective mutants of the wilt pathogen Pseudomonas solanacearum. Appl. Environ. Microbiol. 48:94-101.

Imlay, J. A. 2008. Cellular defenses against superoxide and hydrogen peroxide. Annu. Rev. Biochem. 77:755-776.

Jalloul, A., Montillet, J. L., Assigbetsé, K., Agnel, J. P., Delannoy, E., Triantaphylidès, C., Daniel, J. F., Marmey, P., Geiger, J. P., and Nicole, M. 2002. Lipid peroxidation in cotton: Xanthomonas interactions and the role of lipoxygenases during the hypersensitive reaction. Plant $\mathrm{J}$ 32:1-12.

Jefferson, R. A., Burgess, S. M., and Hirsh, D. 1986. $\beta$-Glucuronidase from Escherichia coli as a gene-fusion marker. Proc. Natl. Acad. Sci. U.S.A. 83:8447-8451.

Jeong, W., Cha, M. K., and Kim, I. H. 2000. Thioredoxin-dependent hydroperoxide peroxidase activity of bacterioferritin comigratory pro- tein (Bcp) as a new member of the thiol-specific antioxidant protein (TSA)/Alkyl hydroperoxide peroxidase C (AhpC) family. J. Biol. Chem. 275:2924-2930.

Kang, Y., Liu, H., Genin, S., Schell, M. A., and Denny, T. P. 2002. Ralstonia solanacearum requires type 4 pili to adhere to multiple surfaces and for natural transformation and virulence. Mol. Microbiol. 46:427-437.

Kao, C. C., Barlow, E., and Sequeira, L. 1992. Extracellular polysaccharide is required for wild-type virulence of Pseudomonas solanacearum. J. Bacteriol. 174:1068-1071.

Kelman, A. 1954. The relationship of pathogenicity of Pseudomonas solanacearum to colony appearance in tetrazolium medium. Phytopathology 44:693-695.

Lamb, C., and Dixon, R. A. 1997. The oxidative burst in plant disease resistance. Annu. Rev. Plant Physiol. Plant Mol. Biol. 48:251-275.

Liu, H., Zhang, S., Schell, M. A., and Denny, T. P. 2005. Pyramiding unmarked deletions in Ralstonia solanacearum shows that secreted proteins in addition to plant cell-wall-degrading enzymes contribute to virulence. Mol. Plant-Microbe Interact. 18:1296-1305.

Loprasert, S., Vattanaviboon, P., Praituan, W., Chamnongpol, S., and Mongkolsuk, S. 1996. Regulation of the oxidative stress protective enzymes, catalase and superoxide dismutase in Xanthomonas-A review. Gene 179:33-37.

Miller, J. H. 1992. A Short Course in Bacterial Genetics: A Laboratory Manual and Handbook for Escherichia coli and Related Bacteria. Cold Spring Harbor Laboratory Press, Cold Spring Harbor, NY, U.S.A.

Oke, V., and Long, S. R. 1999. Bacterial genes induced within the nodule during the Rhizobium-legume symbiosis. Mol. Microbiol. 32:837-849.

Okinaka, Y., Yang, C.-H. Perna, N. T., and Keen, N. T. 2002. Microarray profiling of Erwinia chrysanthemi 3937 genes that are regulated during plant infection. Mol. Plant-Microbe Interact. 15:619-629.

Orozco-Cardenas, M., and Ryan, C. A. 1999. Hydrogen peroxide is generated systemically in plant leaves by wounding and systemin via the octadecanoid pathway. Proc. Natl. Acad. Sci. U.S.A. 96:6553-6557.

Pegg, G. F. 1985. Life in a black-hole-the microenvironment of the vascular pathogen. Trans. Br. Mycol. Soc. 85:1-20.

Rediers, H., Bonnecarrere, V., Rainey, P. B., Hamonts, K., Vanderleyden, J., and De Mot, R. 2003. Development and application of a dapB-based in vivo expression technology system to study colonization of rice by the endophytic nitrogen-fixing bacterium Pseudomonas stutzeri A15. Appl. Environ. Microbiol. 69:6864-6874.

Rediers, H., Rainey, P. B., Vanderleyden, J., and De Mot, R. 2005. Unraveling the secret lives of bacteria: Use of in vivo expression technology and differential fluorescence induction promoter traps as tools for exploring niche-specific gene expression. Microbiol. Mol. Biol. Rev. 69:217-261.

Saenkham, P., Eiamphungporn, W., Farrand, S., Vattanaviboon, P., and Mongkolsuk, S. 2007. Multiple superoxide dismutases in Agrobacterium tumefaciens: Functional analysis, gene regulation, and influence on tumorigenesis. J. Bacteriol. 189:8807-8817.

Salanoubat, M., Genin, S., Artiguenave, F., Gouzy, J., Mangenot, S., Arlat, M., Billault, A., Brottier, P., Camus, J. C., Cattolico, L., Chandler, M. Choisne, N., Claudel-Renard, C., Cunnac, S., Demange, N., Gaspin, C., Lavie, M., Moisan, A., Robert, C., Saurin, W., Schiex, T., Siguier, P. Thebault, P., Whalen, M., Wincker, P., Levy, M., Weissenbach, J., and Boucher, C. A. 2002. Genome sequence of the plant pathogen Ralstonia solanacearum. Nature 415:497-502.

Santos, R., Franza, T., Laporte, M. L., Sauvage, C., Touati, D., and Expert, D. 2001. Essential role of superoxide dismutase on the pathogenicity of Erwinia chrysanthemi strain 3937. Mol. Plant-Microbe Interact 14:758-767.

Schell, M. A. 2000. Control of virulence and pathogenicity genes of Ralstonia solanacearum by an elaborate sensory network. Annu. Rev. Phytopathol. 38:263-292.

Schweizer, H. D. 1993. Small broad-host-range gentamycin resistance gene cassettes for site-specific insertion and deletion mutagenesis. BioTechniques. 15:831-834.

Smith, S. G., Wilson, T. J., Dow, J. M., and Daniels, M. J. 1996. A gene for superoxide dismutase from Xanthomonas campestris pv. campestris and its expression during bacterial-plant interactions. Mol. PlantMicrobe Interact. 9:584-593.

Staskawicz, B., Dahlbeck, D., Keen, N., and Napoli, C. 1987. Molecular characterization of cloned avirulence genes from race 0 and race 1 of Pseudomonas syringae pv. glycinea. J. Bacteriol. 169:5789-5794.

Tamir-Ariel, D., Navon, N., and Burdman, S. 2007. Identification of genes in Xanthomonas campestris pv. vesicatoria induced during Its interaction with tomato. J. Bacteriol. 189:6359-6371.

Tans-Kersten, J., Guan, Y., and Allen, C. 1998. Ralstonia solanacearum pectin methylesterase is required for growth on methylated pectin but not for bacterial wilt virulence. Appl. Environ. Microbiol. 64:4918 4923 
Tans-Kersten, J., Huang, H., and Allen, C. 2001. Ralstonia solanacearum needs motility for invasive virulence on tomato. J. Bacteriol. 183:3597605.

Thurston, H. D. 1976. Resistance to bacterial wilt (Pseudomonas solanacearum). Pages 58-62 in: Planning Conference and Workshops on the Ecology and Control of Bacterial Wilt Caused by Pseudomonas solanacearum. L. Sequeira and A. Kelman, eds. North Carolina State University, Raleigh.

Torres, M., and Dangl, J. 2005. Functions of the respiratory burst oxidase in biotic interactions, abiotic stress and development. Curr. Opin. Plant Biol. 8:397-403.

Venisse, J. S., Gullner, G., and Brisset, M. N. 2001. Evidence for the involvement of an oxidative stress in the initiation of infection of pear by Erwinia amylovora. Plant Physiol. 125:2164-2172.

Wang, G., Olczak, A. A., Walton, J. P., and Maier, R. 2005. Contribution of the Helicobacter pylori thiol peroxidase bacterioferritin comigratory protein to oxidative stress resistance and host colonization. Infect. Immun. 73:378-384.

Xu, X. Q., and Pan, S. Q. 2000. An Agrobacterium catalase is a virulence factor involved in tumorigenesis. Mol. Microbiol. 35:407-414.

Yao, J., and Allen, C. 2006. Chemotaxis is required for virulence and competitive fitness of the bacterial wilt pathogen Ralstonia solanacearum. J. Bacteriol. 188:3697-3708.

Zygmunt, M., Hagius, S., Walker, J., and Elzer, P. H. 2006. Identification of Brucella melitensis 16M genes required for bacterial survival in the caprine host. Microb. Infect. 8:2849-2854.

\section{AUTHOR-RECOMMENDED INTERNET RESOURCES}

Institut National de la Recherche Agronomique Ralstonia solanacearum webpage: bioinfo.genotoul.fr/annotation/iANT/bacteria/ralsto

myCollaborative Annotation Portal Ralstonia solanacearum UW551 project: vision.biotech.ufl.edu/mycap/jsp/project/description.jsp?projectID=1

New England Biolabs NEB Cutter software: tools.neb.com/NEBcutter2/index.php

San Diego Supercomputer Center Biology Workbench tool: workbench.sdsc.edu 